\title{
The Effect of Resources Control Rule Preference on Trust
}

\author{
CHEN Sisi\& ZHU Xianchen \\ School of Economics \& Management, NJUST, Nanjing, Jiangsu, China
}

\begin{abstract}
Trust as a social capital is crucial to society and economic development. In the transitional society, the resources control rule is changing from vertical administrative domination rule to horizontal market coordination rule, leading to individuals' different identities of resources control rule. It is just because the multivariate distribution of rule recognition (preference), trust building between anonymous individuals becomes more difficult. This article just focuses on this problem. We firstly measured individuals' rule preference of resources control, then measure the trust belief and trust action by trust game experiment, and test whether this rule preference will affect trust between anonymous individuals. The results show the following findings: individuals have different rule preference of resources control, and this rule preference have direct influence on trust between individual, that is, the higher degree of identity of vertical administrative domination rule, the lower they trust others.
\end{abstract}

KEYWORD: trust; rule preference; identity of resources control rule; experiment

\section{INTRODUCTION}

In the traditional society of China, the special confidence was built through "overall organization" and concentric personal relationship circles, providing an efficient lubricant for the coordination of social and economic development. However, as the reform process lasts for over three decades, economic and social development becomes more and more market-oriented, and acquaintances pattern of long settlements and small-scale has gradually collapsed, the interpersonal range has expanded from pure blood affection to almost unlimited number of strangers, as a result it is more difficult for people to build trust and cooperation.

For a long period of time, trust is valued as the core of social capital, and provides a stable behavior expectation for interpersonal cooperation whose importance is self-evident. Therefore, trust research has attracted the eyes of various disciplines of researchers Economics deems that when information and computing power of the individual is limited, trust as an informal system reduces transaction costs (North, 1994), and is the result of people's rational choice. The interdisciplinary research on the basis of experience suggests that the gene - culture evolution process (Richerson \& Boyd, 2008; Gintis,2010) endows the individual with preference of certain cultural attributes and norms attributes, these preferences are beyond self-interested ones the traditional economics and biology emphasized, for they can affect people's trust and cooperative behavior. This is the issue that this article concerns: whether and how social preferences carrying cultural and rule attributes affect trust decisions among individuals.

In order to answer this question, we use Hofstede (2001) cultural dimension questionnaire to measure preferences of cultural property, meanwhile, we will use the classic trust game experiments to measure the trust level including trust, faith and trust behavior, examining the influence of cultural dimension attributes and rules attributes to individual trust and attempting to offer a new perspective for the development of trust and cooperation among individuals.

\section{THE LITERATURE REVIEW}

\subsection{Trust and its influencing factors}

Sociologists pay attention to trust the earliest(Simmel,1900) who hold that trust is an important dimension of social relations. It is the psychologists that include trust in systematic study of the theoretical issues the earliest, deeming that trust is a personality trait (Rotter, 1967) or situational reaction (Hosmer, 1995; Deutsh, 1958).

Since Arrow (1974) pointed out that "many of the world economic backwardness can be explained by 
the lack of mutual trust", trust has become an important aspect of economics concerns, and the search for conditions and factors of the trust occurrence also arouses people's attention. The main factors affecting trust can be divided into belief factor and preference factor (Sapienza, 2008): Preference factors mainly include reciprocal preferences, altruistic preferences and risk appetite, while belief is dependent on expectations on the behavior of others.

Existing research on trust in the respect of social preferences pays little attention to rule attribute of social preferences. This type of preference is gradually learned through a long-term process of social evolution and Individual socialization, becoming kernel of formal or informal system by means of sharing knowledge, which is significant for explaining individual micro-decision-making behavior.

\subsection{Expanding of social preference studies}

With the development of interdisciplinary research, based on the perspectives of gene - culture coevolution, the research on the trust started to focus on internalization of rules and socialization process, expanding the connotation of social preferences, introducing cultural values, individual subjective cognitive, social norms and other attributes. Ostrom (2005) investigates trust from the perspective of norm properties of social preferences and sets reciprocity and trust, trust and trustworthiness itself as a specification that the individual will get a positive effect from compliance with the specification, he also pointed out that Only people set trust and reciprocity as basic norms, will it be possible to reach an agreement on a series of operating rules.

For this reason, this article attempts to introduce rule properties of social preference, simplify the rule preferences under certain circumstance and pay attention to the social preferences' impact on individuals in the transforming society with the coexistence of multi rules by referring to the research on cultural dimensions conducted by Anthropology and Sociology (Hofstede, 2001).

\section{THE SURVEY INDICATORS AND EXPERIMENTAL DESIGN}

\subsection{Definition the core concepts}

This article will define trust as a behavior that an individual is willing to make their own interests at the disposal of others in order to obtain the return, or an individual is expected to cooperate with anonymous individuals in a long run. This definition includes acts of trust and beliefs, and the corresponding experimental setup also includes a measure of the level of trust in this two dimensions.

Concerning China's social reality of social preferences in transformation, we simplify the rule attributes, and there are two kinds of rule recognitions governing the functioning of society: bureaucratic vertical administrative rules lasting for thousands of years and recognition of collaboration rule between reform and gradual transformation of the market. Referring to Geert Hofstede's work on cultural dimensions, Select power distance (PDI) and individualism (IDV) to comprehensively reflect China's recognition of two coexistence rules.

\subsection{The design of questionnaire and experimental settings}

Entire questionnaire is designed around individual identity, and the core item is about recognition of social functioning rules, asking whether an individual agrees the statement (using 1-7 Likert scale, from absolute disagree to absolute identity), denoted by Pr. Select the cultural dimensions of power distance investigation (PDI) and Individualism (IDV) as two dimensions of questionnaire items (2008 version, VSM08).

Using Breg et. Al (1995) classic trust experimental setup, client $\mathrm{A}$ and agent $\mathrm{B}$ are divided into two teams, A to obtain $S, S=50$ initial endowment, take out $\mathrm{y} \in[0-\mathrm{S}]$ wealth to $\mathrm{B}$, after reaching the hands of the $B$, the value is $3 y$, then it's up to $B$ to decide to return to the $A$ the wealth $x, x \in$ [0-3y]. Reference Ernesto et.al (2009) trust decision setup, increase measure of the faith of A about B return, and build trust indicators. Including three decision tasks: Decision 1- the amount B decided to offer to give y denoted $\mathrm{Ag} \in[0,50]$; Decision2- the amount A believes $\mathrm{B}$ shall return records $\mathrm{ABs} \in[0,3 \mathrm{Ag}]$, and the estimated return of $\mathrm{B}$ may actually recorded as $\mathrm{ABm} \in[0,3 \mathrm{Ag}]$; Decision3-If $\mathrm{B}$ receives $3 \mathrm{Ag}$, the amount he is willing to refund recorded as $\mathrm{Bg} \in[0,3 \mathrm{Ag}] ; 3 \mathrm{~S}$ as $\mathrm{B}$ If $\mathrm{B}$ receives the maximum return value $3 \mathrm{~S}$, recorded $\mathrm{Bgm} \in[0,150]$;

In this paper, according to the definition of trust, the amount that the client A willing to invest to agent $\mathrm{B}$ as a measure of confidence indicators is denoted trust_index1; the expectation client A to Agent B's return act is the faith indicator, including the faith that other party should return and convictions that the possibility of return, which are recorded as trust_index 2 and trust_index 3 .

\section{THR RESULTS OF THE EXPERIMENT}

\subsection{Descriptive statistics}

\subsubsection{Questionnaire}

The questionnaire aims to investigate the recognition of resource governing rules, and the core indicators are recognition "care - dependent, dominate - 
obedience" relationship that Pr reflects, what's more the paper will further argue combined with question items of cultural dimensions and World Values Survey.

The correlation coefficient between variables to some extent validates the idea of Table 1, as the rule preference learned in the course of socialization has specific cultural attributes, namely, individual $\operatorname{Pr}$ is associated with PDI and IDV. PDI has significant positive correlation with $\operatorname{Pr}(\mathrm{r}=-0.212, \mathrm{p}=0.03)$, that is, the higher the expectation and acceptance level of unequal power distribution between the government, the more likely to accept "care dependent, dominate - obedience" relations; There is a negative correlation between IDV $\mathrm{Pr}$ and, but not so significant $(\mathrm{r}=-0.119, \mathrm{p}=0.228)$.

In conclusion, the individual's resources governing norms and rule preference presents multivariate distribution, there is different identity level of "care - dependent, dominate - obedience "relations, and this rule has preferences carrying certain cultural attributes.
Table1. The correlation coefficient between variables

\begin{tabular}{|l|l|l|l|l|l|l|}
\hline & sex & eco & Pr & Po & PDI & IDV \\
\hline sex & 1 & & & & & \\
\hline eco & $-0.213^{* *}$ & 1 & & & & \\
\hline Pr & 0.089 & 0.019 & 1 & & & \\
\hline Po & $0.218^{* *}$ & -0.153 & 0.035 & 1 & & \\
\hline PDI & 0.098 & 0.05 & $0.212^{* *}$ & 0.011 & 1 & \\
\hline IDV & -0.042 & 0.029 & -0.119 & -0.049 & -0.051 & 1 \\
\hline
\end{tabular}

\subsubsection{Trust experiment}

Table 2 summarizes all spearman correlation coefficient of variables, indicating that there is a negative correlation between trust_index 2 and trust_index3, the maximum output of fair distribution preference cooperation Po are positive with three trust indexes; at the same time, IDV is positively correlated with the level of faith, a significant positive correlation among the three trust indexes.

Table2. Questionnaire and correlation coefficient

\begin{tabular}{|c|c|c|c|c|c|c|c|}
\hline & Pr & Po & PDI & IDV & trust_index1 & trust_index2 & trust_index3 \\
\hline Pr & 1 & & & & & \\
\hline Po & 0.035 & 1 & & & & \\
\hline PDI & $0.212^{* * *}$ & 0.011 & 1 & & & \\
\hline IDV & -0.119 & -0.049 & -0.051 & 1 & & \\
\hline trust_index1 & -0.05 & $0.335^{* * *}$ & -0.004 & -0.022 & 1 & & \\
\hline trust_index2 & $-0.181^{*}$ & $0.293^{* * *}$ & -0.031 & $0.174^{*}$ & $0.580^{* * *}$ & 1 \\
\hline trust_index3 & $-0.184^{*}$ & $0.191^{*}$ & -0.092 & $0.171^{*}$ & $0.554^{* * *}$ & $0.585^{* *}$ & 1 \\
\hline
\end{tabular}

\subsection{Statistical test}

According to care-dependent, dominantsubordinate" relationship to divide groups, if acceptance level is no lower than 3 , it is divided into high acceptance Pr group (referred to as $\mathrm{Pr} \_\mathrm{H}, 74$ people), if the degree is less than 3 , it is in low acceptance Pr group (denoted as Pr_L, 31 people). Test results are shown in Table3.

Table3. The distribution hypothesis testing

\begin{tabular}{|c|c|c|c|c|c|c|}
\hline & & & Pr_H (74) & Pr_L (31) & $\mathrm{t}$ or $\mathrm{z}$ & $\mathrm{P}-$ \\
\hline \multirow{6}{*}{ t-test } & \multirow{2}{*}{ trust_index1 } & Mean & 5.2514 & 5.4839 & \multirow{2}{*}{0.411} & \multirow{2}{*}{0.683} \\
\hline & & S. D & 3.096 & 2.4341 & & \\
\hline & \multirow{2}{*}{ trust_index 2} & Mean & .7203 & .9645 & \multirow{2}{*}{1.931} & \multirow{2}{*}{0.056} \\
\hline & & S. D & .6050 & .5565 & & \\
\hline & \multirow{2}{*}{ trust_index3 } & Mean & 0.9801 & 1.1294 & \multirow{2}{*}{1.416} & \multirow{2}{*}{0.160} \\
\hline & & S. D & 0.50362 & .4641 & & \\
\hline \multirow{6}{*}{$\begin{array}{c}\text { Mann-Whitney } \\
\text { U test }\end{array}$} & \multirow{2}{*}{ trust_index 1} & Mean Rank & 51.58 & 56.39 & \multirow{2}{*}{-0.745} & \multirow{2}{*}{0.456} \\
\hline & & Sun of Rand & 3817.00 & 1748.00 & & \\
\hline & \multirow{2}{*}{ trust_index 2} & Mean Rank & 49.26 & 61.92 & \multirow{2}{*}{-1.965} & \multirow{2}{*}{0.049} \\
\hline & & Sun of Rand & 3645.50 & 1919.50 & & \\
\hline & \multirow{2}{*}{ trust_index 3} & Mean Rank & 49.96 & 3697.00 & \multirow{2}{*}{-1.604} & \multirow{2}{*}{0.106} \\
\hline & & Sun of Rand & 60.26 & 1868.00 & & \\
\hline
\end{tabular}


T-test results show that the value of high acceptance group is lower than the low acceptance group both in the mean of the three trust index and identity of vertical extent of the administrative rules. However, only "subjective estimates of $\mathrm{A}$ on the degree of B's return" reflects significant difference in faith $(\mathrm{t}=1.931, \mathrm{p}=0.056)$. Mann-Whitney $\mathrm{U}$ test show the distribution of trust_index 2 is significantly different $(Z=-1.965, p=0.049)$, while the difference between trust_index 3 and index trust_index 1 is not significant. In this regard, we can imply that: Rule preference mainly acts on trust_index 2 and trust_index 3 , but direct effect on trust_index 1 is not obvious, this article will verify in the multiple regression.

\subsection{Multiple Regression}

In order to further discuss the impact of various factors on the level of trust, trust_index1, trust_index2, trust_index3 are explained variables, select Pr, Po and PDI, IDV and gender and professional eco to conduct multiple regression analysis.

First examine the direct impact of recognition of resources control rules on the level of trust, the regression results in Table 6 . Regression equations 3 and 5 show that preference rules Pr has significant contributions for the explanation of both ; regression equation 4 and 6 show when two variables, PDI and IDV rules, added, rule preference $\mathrm{Pr}$ is still significant for interpretation, while IDV has significant influence on the two trust index. The preference of results distribution recognition also has significant explanatory contribution.

In other words, the higher the recognition level of "care - dependence, domination - subject to" rules, the less likely to accept cooperate among anonymous individuals; at the same time, according to Hofstedes (2001) definition of impact of the cultural dimensions on individualism, individuals of high individualism have higher level of acceptance of anonymous individual impersonal exchanges showing a higher level of trust in faith.

Taking trust_index 1 as explained variables, the estimated expressions 1 and 2 show that the rule preference Pr, PDI and IDV do not have significant explainary contribution, while Po contributes significantly; individuals of higher level of maximum output distribution cooperation preference have a strong tendency of anonymous cooperation action. Meanwhile, gender also has influences, male has a high level in "trust action" in anonymous cooperation.

Table 4 Multiple regression results

\begin{tabular}{|c|c|c|c|c|c|c|}
\hline & \multicolumn{2}{|c|}{ trust_index1 } & \multicolumn{2}{c|}{ trust_index2 } & \multicolumn{2}{c|}{ trust_index3 } \\
\hline & 1 & 2 & 3 & 4 & 5 \\
\hline sex & $1.116^{*}$ & $1.138^{*}$ & 0.082 & 0.091 & 0.104 & 0.118 \\
\hline eco & 0.896 & 0.91 & 0.058 & 0.053 & 0.054 & 0.054 \\
\hline Pr & -0.086 & -0.057 & $-0.085^{* *}$ & $-0.079^{*}$ & $-0.073^{* *}$ & $-0.058^{*}$ \\
\hline PDI & & -0.027 & & 0.001 & -0.009 \\
\hline IDV & & 0.003 & & 0.0214 & $0.018^{*}$ \\
\hline Po & $5.039 * * *$ & $5.035^{* * *}$ & $1.126^{* * *}$ & $1.203^{* * *}$ & 0.478 & $0.537^{*}$ \\
\hline cons & $2.716^{* * *}$ & $2.62^{* * *}$ & $0.566^{* *}$ & $0.566^{* * *}$ & $1.008^{* * *}$ & $0.974 * * *(0.203)$ \\
\hline R-squared & 0.129 & 0.13 & 0.134 & 0.172 & 0.074 & 0.112 \\
\hline F & 4.65 & 3.19 & 4.54 & 4.52 & 2.84 & 3.07 \\
\hline observations & 105 & 105 & 105 & 105 & 105 & 105 \\
\hline
\end{tabular}

\section{CONCLUSION}

In transformation society, with the transforming process from al vertical administrative rules to horizontal market coordination of resources rules, the rules individuals holdings have gradually changed, it is the multivariate distributions of identity (preference) that makes it increasingly difficult to establish trust between anonymous individuals. The core issues in this article: Individual's acceptance of "preference of resource control rules" - the recognition vertical administrative rules, whether will impact on the level of trust in anonymous cooperation when such social preference as allocation results of property plays a role.

We draw the following conclusions:

Conclusion 1: Individuals have different preferences for resource control rules, and have different acceptance level of vertical administrative rules with "care - dependence, domination obedience" as the main content. Such rule preferences are acquired later carrying certain cultural property;

Conclusion 2: The acceptance degree of vertical administrative rules significantly affects individuals' trust and faith: Individuals who have a high level of acceptance of vertical administrative rules have 
lower faith than those who have low level of acceptance;

Conclusion 3: The maximum output of fair distribution preference has a significant influence on trust: The maximum output of fair distribution preference has significant positive effect on both trust action and faith.

\section{REFERENCES}

[1] Arrow K.J.1998.The Place ofInstitutions in the Economy: A Theoretical Perspective. In Y. Hayami and M. Aoki (eds.), the Institutional Foundations of East Asian Economic Development. Basingstoke: Macmillan.

[2] Bowles, S.2004. Microeconomics: behavior, institutions and evolution. Princeton: Princeton University Press.

[3] Deutsch, M. 1958.Trust and suspicion. Journal of Conflict Resolution, 2,265 279.
[4] Herbert • Jin Disi Dong Zhiqiang translation .2010 Border of Ration: Game Theory and the unity of the Behavioral Sciences Shanghai: Polytechnic Press, Joint Publishing, Shanghai People's Publishing House.

[5] Hofstede G H.2001.Culture's consequences: Comparing values, behaviors, institutions and organizations across nations. Sage.

[6] Hosmer.L.t.1995.Trust: The connecting link between organizational theory and philosophical ethics..Academy of Management Review. 20(2), 379 403.

[7] Knack S, Keefer.1997. Does social capital have an economic payoff: A cross-country inves-igation. Quarterly Journal of Economics, Vol.112. (4): 1251 88.

[8] Knack S.P \&J.Zack2001..Building trust: Public policy, interpersonal trust, and economic development. Supreme Court Economic Review.

[9] North D C. 1994.Transaction costs through time. EconWPA.

[10] Simmel, Chen Rongnv translation .2002 Currency Philosophy Beijing: China Press: p178-179. 